\title{
Loss of ACE2 accelerates time-dependent glomerular and tubulointerstitial damage in streptozotocin- induced diabetic mice
}

\author{
Atsushi Shiota, Koichi Yamamoto, Mitsuru Ohishi, Yuji Tatara, Miyuki Ohnishi, Yoshihiro Maekawa, \\ Yoshihiro Iwamoto, Masao Takeda and Hiromi Rakugi
}

As angiotensin-converting enzyme-2 (ACE2) was identified as a negative regulator of the renin-angiotensin system, there have been many reports concerning its role in several tissues, including the kidney. However, the role of ACE2 during the development of diabetic nephropathy remains undetermined, as previous reports did not necessarily support a protective role against renal injury. Thus, we performed detailed observations of kidneys in ACE2-knockout (ACE2-KO) mice at early (4 weeks) and advanced (18 weeks) stages of diabetes. ACE2-KO and wild-type C57BL/6 mice were rendered diabetic by intraperitoneal injection of streptozotocin. Diabetic ACE2-KO mice showed earlier onset and more severe progression of albuminuria than those did wild-type mice. The elevation of serum creatinine and urea nitrogen levels at 18 weeks of diabetes was more prominent in ACE2-KO mice. Periodic acid-Schiff-stained cross-section of diabetic ACE2-KO mice showed a more severe time-dependent increase in glomerular/tubulointerstitial damage than did that of wild-type mice, confirmed by the immunostaining of $\alpha$-smooth muscle actin, collagen IV and F4-80 antigen. Glomeruli of diabetic ACE2-KO mice showed earlier and more severe decrease in the expression of nephrin, whose degradation is involved in the onset of albuminuria, and more potent increase of vascular endothelial growth factor expression. In addition, treatment with AT1 receptor blocker olmesartan significantly, but not totally, ameliorated the functional and morphological deterioration of diabetic nephropathy in ACE2-KO mice. These results suggest that ACE2 might continuously protect from both glomerular and tubulointerstitial injury during the development of diabetic nephropathy. The renal-protective effect of ACE2 might involve more than just suppressing angiotensin II-mediated AT1 receptor signaling.

Hypertension Research (2010) 33, 298-307; doi:10.1038/hr.2009.231; published online 26 February 2010

Keywords: ACE2; diabetic nephropathy; renin-angiotensin system

\section{INTRODUCTION}

The renin-angiotensin system (RAS) has a key role in the development of many renal diseases and blocking this system is an established therapeutic target for preserving kidney function in several chronic kidney diseases. ${ }^{1-5}$ In particular, use of an angiotensin-converting enzyme (ACE) inhibitor or AT1 subtype angiotensin II receptor blocker (ARB) in diabetic nephropathy, currently one of the most common reasons for chronic dialysis, reduced the progression of kidney dysfunction in several clinical trials. ${ }^{1-3}$ ACE inhibitors or ARBs in diabetic nephropathy contributes to renal protection not only by reducing renal artery pressure but also by blocking angiotensin II (Ang II)-induced cellular signaling that is increased in such conditions and damages several types of kidney cells. Thus, to understand the pathophysiology of diabetic nephropathy, it is important to comprehend the mechanism regulating Ang II signaling.

Angiotensin-converting enzyme-2 (ACE2) is a membrane-bound carboxymonopeptidase containing a single enzymatic site. It cleaves
Ang II at a single residue to generate angiotensin 1-7 (Ang 1-7). The expression of ACE2 is observed in many tissues, including the heart, aorta, lung and kidney. ACE2 is thought to function as a negative regulator of the RAS by degrading Ang II and producing Ang 1-7 to counterbalance the Ang II-forming activity of ACE.

In the kidney, ACE2 is reported to be localized in renal tubules and glomeruli, ${ }^{8-11}$ and several studies showed that the expression of ACE2 is reduced during the development of diabetic nephropathy. ${ }^{10,12,13}$ To investigate the functional significance of ACE2 in diabetic nephropathy, several in vivo studies were performed; some administered ACE2 inhibitor, others carried a targeted disruption of the ACE2 gene to diabetic mice. In the reports of Soler et al. ${ }^{14}$ and Ye et al. ${ }^{8}$ diabetic mice treated by specific ACE2 inhibitor MLN-4760 showed increased albuminuria and glomerular/tubular injury compared with untreated diabetic mice. As for the studies using ACE2-knockout (ACE2-KO) mice, Wong et al. ${ }^{15}$ used ACE2-KO mice bred with diabetic AKITA mice, and Tikellis et al. ${ }^{16}$ generated diabetic ACE2-KO mice by 
injecting the mice with streptozotocin to assess the influence of ACE2 on pathology and renal function in diabetic nephropathy. Although they showed similar results in terms of increased albumin excretion ratio with deletion of ACE2, there were differences between the two studies with regard to pathological changes after induction of diabetic nephropathy. In the report of Wong et al., deletion of ACE2 resulted in enhanced glomerular hypertrophy and interstitial fibrosis at 3 months of age, whereas renal hypertrophy and expression of fibrotic markers were attenuated in diabetic ACE2-KO mice of Tikellis et al. at 10 weeks of diabetes. In addition, the influence of ACE2 on sequential changes in renal pathophysiology during development of diabetic nephropathy remains unknown, as renal pathophysiological assessment was performed at one time point in each study. Thus, their findings raised the possibility that a role of ACE2 in diabetic nephropathy might vary according to the duration or severity of diabetes. Therefore, we compared renal pathophysiological changes of streptozotocinadministered ACE2-KO mice with those of wild-type mice at the early (4 weeks) and advanced (18 weeks) stages of diabetes, to investigate a sequential role of ACE2 during development of diabetic nephropathy. Also, we used ARB to investigate whether diabetic ACE2-KO and wild-type mice exhibited any difference in renal phenotype in the absence of AT1 signaling.

\section{METHODS}

\section{Animal model}

The creation of the ACE2-deficient mice was previously described. ${ }^{17}$ All animals were housed at the Institute of Laboratory Animals at Osaka University. These animals were studied in accordance with the NIH Guide for the Care and Use of Laboratory Animals and were placed on a protocol approved by the Animal Research Committee of the Osaka University.

\section{Experimental protocol}

Male ACE2-KO (-/y) and wild-type (+/y) littermates were bred from ACE2+/y male and ACE2-/+ female mice with a C57BL/6N background. Six- to eightweek-old ACE2-KO and wild-type littermates were rendered diabetic after 5 daily intraperitoneal injections of streptozotocin at a dose of $55 \mathrm{mg} \mathrm{kg}^{-1}$ in $10 \mathrm{~mm}$ citrate buffer. ${ }^{18}$ Mice with blood glucose levels of $>350 \mathrm{mg}$ per $100 \mathrm{ml}$ 7 days after the last injection were included in this study. The mice had free access to water and standard mouse chow. Treatment with AT1 receptor blocker Olmesartan (Sankyo Corporation, Tokyo, Japan) to some mice was started a week before the injection of streptozotocin and continued during the follow-up period. Olmesartan was administered in drinking water to obtain a dose of $4 \mathrm{mg} \mathrm{kg}^{-1}$ day $^{-1} \cdot{ }^{19-21}$

Four or 18 weeks after induction of diabetes, the animals were anesthetized by an intraperitoneal injection of pentobarbital sodium. Blood was collected from the inferior vena cava and then centrifuged to obtain serum or was stored as plasma, with addition of phenylmethylsulfonyl fluoride and EDTA, for subsequent analyses. Kidneys were dissected and immediately snap-frozen (for protein extraction) or stored in $4 \%$ neutral buffered formalin (for histological studies) or immediately homogenized (for determination of Ang II concentrations). We performed these experiments 4 weeks after induction of diabetes on the basis of previous reports in which the early phase of urinary albumin excretion was detected in streptozotocin-induced diabetic C57BL/6 mice at this time point. ${ }^{22}$ The 18 -week period was also based on previous reports showing that diabetic C57BL/6 mice begin to show morphological and functional kidney changes 16 to 20 weeks after induction of diabetes. ${ }^{18,23}$

\section{Physiological and biochemical analysis}

Glucose levels in fresh tail vein blood were measured every week during the first 4 weeks, and then at 8,12 and 18 weeks after the induction of diabetes in non-fasted mice by Glucose Vision (Aventir Biotech, LLC, Carlsbad, CA, USA). Serum creatinine, urea nitrogen and natrium concentrations were measured at the Nissei Bilis Corporation (Osaka, Japan).
To assess urine albumin excretion, animals were placed in metabolic cages for 24-h urine collection. Albumin concentrations were measured using the ELISA kit Albuwell M Assay Kit (Exocel, Philadelphia, PA, USA) according to the manufacturer's instructions. Blood pressure was measured using a noninvasive tail-cuff method in conscious mice.

\section{Renal pathology}

Formalin-fixed kidneys were embedded in paraffin. Then $2 \mu \mathrm{m}$ sections were stained with periodic acid-Schiff. Digital images were obtained from microscopy, and the degree of renal lesions was assessed in a blinded manner using previously described semiquantitative methods with minor modifications. ${ }^{18,24}$ As an evaluation of glomerular injury, all glomeruli in each kidney section were graded on periodic acid-Schiff-stained sections according to the severity of the glomerular damage, which included mesangial matrix expansion and/or hyalinosis with focal adhesions, capillary dilation, and true glomerular occlusion and sclerosis: grade 0 , intact glomerulus; grade 1, glomerular injury involving $<25 \%$ of the glomerulus; grade $2,25-50 \%$; grade $3,50-75 \%$; grade 4 , severe damage or sclerosis involving $>75 \%$ of the glomerulus. For tubulointerstitial injury, 20 microscopic fields $(\times 200)$ from the cortex in each kidney section were randomly selected. Tubular lesions were graded according to the severity of tubular dilations and/or atrophy: grade 0 , no tubular injury; grade $1,<25 \%$ of the field involved; grade 2, 25-50\%; grade 3, $50-75 \%$; grade $4,>75 \%$.

These indices of glomerular/tubulointerstitial injuries were calculated by averaging the grades assigned to the glomeruli/tubulointerstitial fields.

\section{Immunohistochemistry}

The primary antibodies for immunostaining were as follows: anti- $\alpha$-smooth muscle actin ( $\alpha$-SMA, Dako Japan, Kyoto, Japan), anti-collagen type IV (Southern Biotechnology Associates, Birmingham, AL, USA), anti-nephrin (Santa Cruz Biotechnology, Santa Cruz, CA, USA), anti-vascular endothelial growth factor (VEGF, EMD Chemicals, Darmstadt, Germany) and anti-mouse tissue macrophage antibody (anti-F4/80 antibody, Serotec, Oxford, UK). In brief, sections were dewaxed and hydrated, and antigen retrieval was performed by proteinase K purchased from Dako Japan. Endogenous peroxidase activity was blocked by Dako REAL Peroxidase Blocking Solution, and then the sections were incubated with the primary antibodies for $12 \mathrm{~h}$ at $4{ }^{\circ} \mathrm{C}$. As the secondary antibody, ENVISION+ mouse (Dako Japan) was applied in a humid atmosphere for $30 \mathrm{~min}$. For the chromogen development, DAB+ reagent (Dako Japan) was applied for $10 \mathrm{~min}$. After staining, the sections were counterstained with Mayer's hematoxylin.

The assessment was as follows: F4/80-positive macrophages were counted in 20 randomly selected microscopic fields $(\times 400)$ per animal and expressed as the mean number of cells per field. For assessment of glomerular nephrin staining, which was generally too weak to assess by computer software, a semiquantitative analysis was performed on the basis of a pathologistestablished score, as previously described. ${ }^{8}$ Briefly, 1, no staining; 2, weak staining; and 3, strong staining. Then, the percentage of glomeruli with strong staining was calculated for each animal. As for other immunostaining, the percent positive staining area was calculated within 20 randomly selected glomerular tufts or cortical tubulointerstitial areas by computer image analysis using Image J software (http://rsb.info.nih.gov/ij/). All sections were examined by three different blinded observers.

\section{Plasma and kidney Ang II concentration}

After blood collection from the inferior vena cava and adequate perfusion with heparinized saline, the isolated kidney was homogenized on ice in $0.9 \%$ saline/ $0.1 \mathrm{~mol} / \mathrm{l} \mathrm{HCl}$ containing $0.1 \mathrm{~mol} / \mathrm{l}$ aprotinin. The total protein content of an aliquot of the homogenate was determined using the Bradford protein assay. Peptide extraction was performed as previously described. ${ }^{17}$ Ang II concentration was measured by radioimmunoassay using two antibodies specific for Ang II (SRL Corporation, Tokyo, Japan) and described as $\mathrm{pg} \mathrm{ml}^{-1}$ (plasma) or $\mathrm{pg} \mathrm{mg}^{-1}$ protein (kidney). This antibody has cross-reactivity with angiotensin I and III of $<0.1$ and $21 \%$, respectively. 


\section{Statistical analysis}

Data were analyzed with Stat View version 4.51 and are presented as the mean \pm s.e.m. Statistical analysis was performed using the two-tailed Student's $t$-test and analysis of variance where applicable. Multiple group comparisons were carried out by analysis of variance with Fisher's post hoc comparison. A value of $P$ less than 0.05 was considered statistically significant.

\section{RESULTS}

\section{Physiological and biochemical markers of diabetic mice}

At first, we bred nondiabetic ACE2-KO mice and wild-type littermates (6 weeks of age at the beginning of the study) for 18 weeks. Those nondiabetic ACE2-KO mice had similar body weight, blood pressure, kidney weight and other metabolic markers, including albuminuria, compared with wild type both at baseline and 18 weeks later (Supplementary Table). Eighteen weeks after administration of streptozotocin, blood sugar levels of ACE2-KO and wildtype mice were equally elevated (Table 1). Neither diabetic ACE2-KO nor wild-type mice showed body weight loss compared with agematched nondiabetic mice. Diabetes was associated with an increase in serum creatinine and urea nitrogen levels in both strains, but a significantly larger elevation was observed in ACE2-KO mice. Mean blood pressure was not changed after the onset of diabetes in either mouse strain and kidney weight increased similarly in both strains. Heart weight was not affected by ACE2 deletion or the onset of diabetes.

Streptozotocin-induced diabetes was accompanied by time-dependent development of albuminuria in both ACE2-KO and wild-type mice. However, onset and elevation of albuminuria occurred earlier in ACE2-KO mice, and was more severe than in wild-type mice (4 weeks after induction of diabetes, ACE2-KO $=48.9 \pm 12.6 \mu \mathrm{g}$ per $100 \mathrm{ml}$ vs. wild type $=24.8 \pm 11.7 \mu \mathrm{g}$ per $100 \mathrm{ml} ; P<0.05)$. The enhanced excretion of albuminuria in ACE-KO mice was observed up to 18 weeks after induction of diabetes, the end of the follow-up period (18 weeks after induction of diabetes, ACE2$\mathrm{KO}=87.7 \pm 21.9 \mu \mathrm{g}$ per $100 \mathrm{ml}$ vs. wild type $=49.3 \pm 16.3 \mu \mathrm{g}$ per $100 \mathrm{ml} ; P<0.05$ ) (Figure 1a).

\section{Plasma and kidney Ang II concentrations in ACE-KO and wild-type mice}

Nondiabetic ACE2-KO mice had higher kidney Ang II concentrations than nondiabetic wild-type mice (Table 2), which was consistent with a previous report by Crackower et al. ${ }^{25}$ Four weeks after the onset of diabetes, tissue Ang II was increased both in the kidneys of ACE2-KO and wild-type mice, and the difference between the two groups disappeared $(P=0.32)$. In contrast, there was no difference in plasma Ang II concentrations between ACE2-KO and wild-type mice, before or after diabetes induction.

\section{Glomerular and tubulointerstitial injury in diabetic mice}

The kidneys of nondiabetic ACE2-KO and wild-type mice at baseline and 18 weeks later showed no structural abnormalities under light microscopy (Supplementary Figure). Four weeks after diabetes induction, ACE2-KO mice showed mild glomerular injury including glomerular hypertrophy, mesangial matrix expansion and mesangial hypercellularity. Eighteen weeks after streptozotocin injection, these changes were significantly more severe in ACE2-KO mice than in age-matched wild-type mice. Some glomeruli in 18-week diabetic ACE2-KO mice showed more progressive changes, including glomerulosclerosis and atrophy, reflected as an increased semiquantitative glomerular injury index (Figure 1).

Similarly, tubulointerstitial injuries were also accelerated in diabetic ACE2-KO mice. Although both ACE2-KO and wild-type mice showed almost normal tubulointerstitium under light microscopy at baseline, diabetic ACE2-KO mice had increased number of dilated or atrophied tubules compared with age-matched wild-type mice (Figure 1).

\section{Localization and expression of proteins indicative of kidney injury in diabetic mice}

Immunohistochemical studies were performed to characterize kidney injury in the diabetic state using antibodies against proteins well known to be upregulated in diabetic nephropathy. There was a greater time-dependent increase in glomerular $\alpha$-smooth muscle actin and glomerular/interstitial collagen IV in diabetic ACE2-KO mice than in wild-type mice, confirming accelerated diabetic glomerular and tubulointerstitial injury in ACE2-KO mice (Figure 2).

To evaluate macrophage infiltration as an important aspect of tubulointerstitial injury, F4/80 immunostaining was performed. Similar to the case of $\alpha$-SMA and collagen IV, there was a time-dependent increase in the number of interstitial macrophages and the change was earlier and greater in diabetic ACE2-KO mice than in wild-type mice (Figure 3).

We also performed immunohistochemistry to find other factors involved in accelerated functional and morphological abnormalities in diabetic ACE2-KO mice. Glomeruli of early diabetic mice showed decreased expression of nephrin, comparable with previous reports. ${ }^{26-28}$ In addition, the change was greater in diabetic ACE2-KO mice than in

Table 1 Physiological and biochemical parameters

\begin{tabular}{|c|c|c|c|c|}
\hline & $\begin{array}{c}\text { Nondiabetic } \\
\text { wildtype }(\mathrm{n}=10)\end{array}$ & $\begin{array}{c}\text { Nondiabetic } \\
\text { ACE2-KO }(\mathrm{n}=10)\end{array}$ & $\begin{array}{l}18 \text { Weeks diabetic } \\
\text { wildtype }(\mathrm{n}=10)\end{array}$ & $\begin{array}{l}18 \text { Weeks diabetic } \\
\text { ACE2-KO }(\mathrm{n}=10)\end{array}$ \\
\hline Body weight (g) & $32 \pm 2.9$ & $34 \pm 1.9$ & $28 \pm 5.4$ & $30 \pm 4.7$ \\
\hline Mean blood pressure $(\mathrm{mm} \mathrm{Hg})$ & $77 \pm 12.4$ & $84 \pm 6.72$ & $76 \pm 11.3$ & $88 \pm 8.31$ \\
\hline Blood glucose $\left(\mathrm{mmol} \mathrm{I}^{-1}\right)$ & $14.2 \pm 1.38$ & $12.4 \pm 2.62$ & $24.0 \pm 3.85^{*}$ & $25.2 \pm 4.81 *$ \\
\hline Serum creatinine $\left(\mu \mathrm{mol} \mathrm{I}^{-1}\right)$ & $16 \pm 1.24$ & $13 \pm 2.75$ & $23 \pm 0.97$ & $36 \pm 5.8^{*, \dagger}$ \\
\hline Serum urea nitrogen $\left(\mathrm{mmoll}^{-1}\right)$ & $9.7 \pm 0.47$ & $10 \pm 0.93$ & $13 \pm 0.41^{*}$ & $19 \pm 1.3^{*, \dagger}$ \\
\hline Serum $\mathrm{Na}\left(\mathrm{mmol}^{-1}\right)$ & $142 \pm 2.0$ & $139 \pm 3.8$ & $144 \pm 11$ & $145 \pm 9.1$ \\
\hline Kidney weight (mg) & $178 \pm 11.6$ & $166 \pm 21.0$ & $234 \pm 24.1 *$ & $242 \pm 36.7 *$ \\
\hline Heart weight (mg) & $137 \pm 8.50$ & $125 \pm 16.0$ & $126 \pm 19.5$ & $133 \pm 25.3$ \\
\hline
\end{tabular}

Abbreviation: ACE2-KO, angiotensin-converting enzyme-2-knockout.

All nondiabetic and diabetic mice were age-matched. Data are presented as mean \pm s.e.m. ${ }^{*} P<0.05$ vs. genotype-matched nondiabetic group, and ${ }^{\dagger} P<0.05$ vs. diabetic wildtype. 

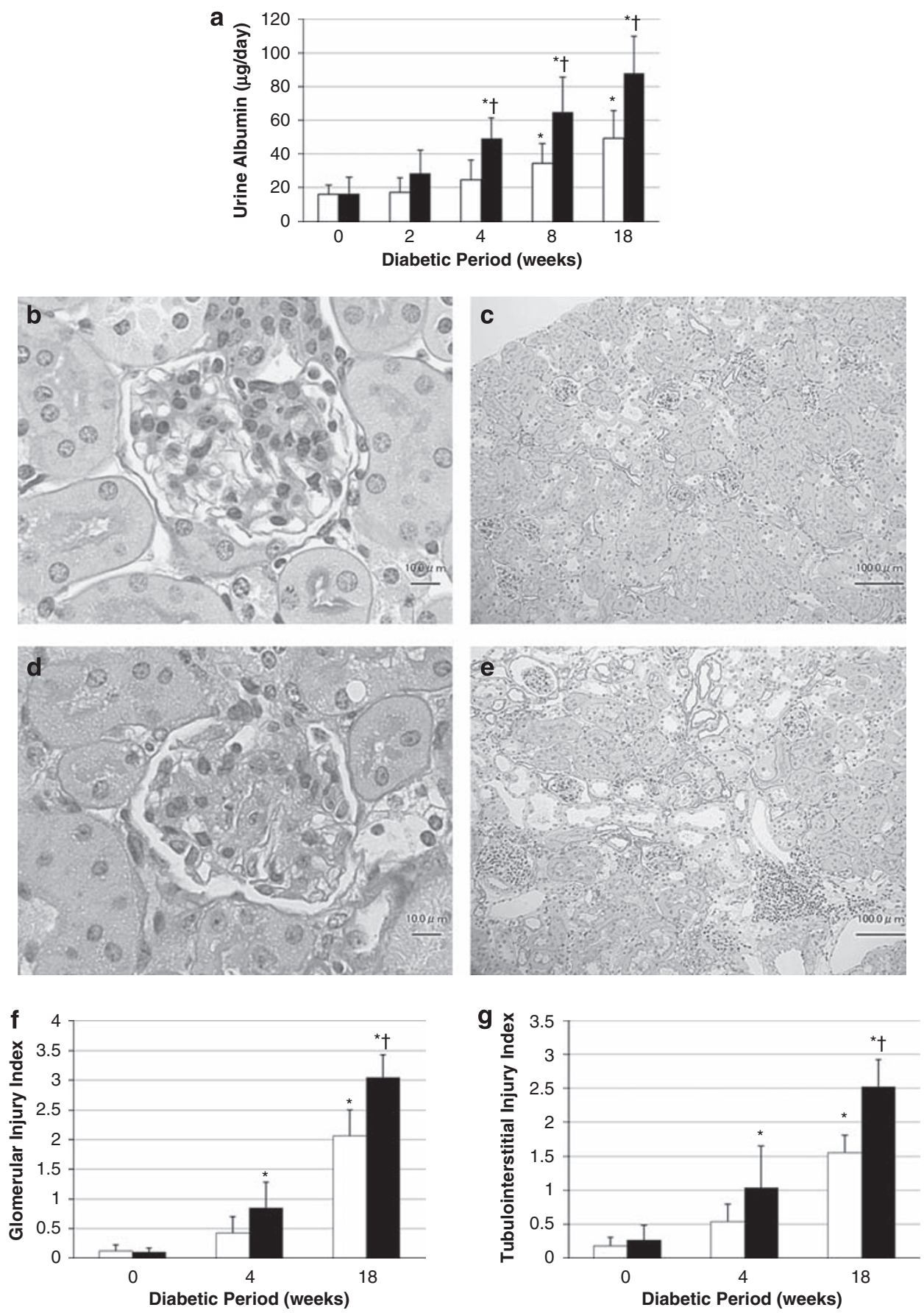

Figure 1 (a) Daily urinary albumin excretion of ACE2-KO and wild-type mice at various time points after induction of diabetes determined by ELISA. (b-e) Representative photomicrographs of glomeruli and tubulointerstitium in PAS-stained kidney sections from wild-type (b, c) and ACE2-KO mice (d, e) 18 weeks after induction of diabetes. Original magnifications $\times 800$ and $\times 200$. (f, g) Glomerular and tubulointerstitial injury index by semiquantitative analysis. White bars=wildtype $(n=10)$; black bars=ACE2-KO $(n=10)$. Data are presented as mean \pm s.e.m. ${ }^{*} P<0.05$ compared with a genotype-matched baseline group, and ${ }^{\dagger} P<0.05$ compared with age-matched wildtype.

Table 2 Tissue/plasma Angiotensin (Ang) II concentration

\begin{tabular}{|c|c|c|c|c|c|c|}
\hline Plasma Ang II (pg ml $\left.{ }^{-1}\right)$ & $53.8 \pm 9.1$ & $47.3 \pm 13.2$ & $64 \pm 19.8$ & $51.5 \pm 20.1$ & $64.3 \pm 24.1$ & $49.8 \pm 17.6$ \\
\hline
\end{tabular}



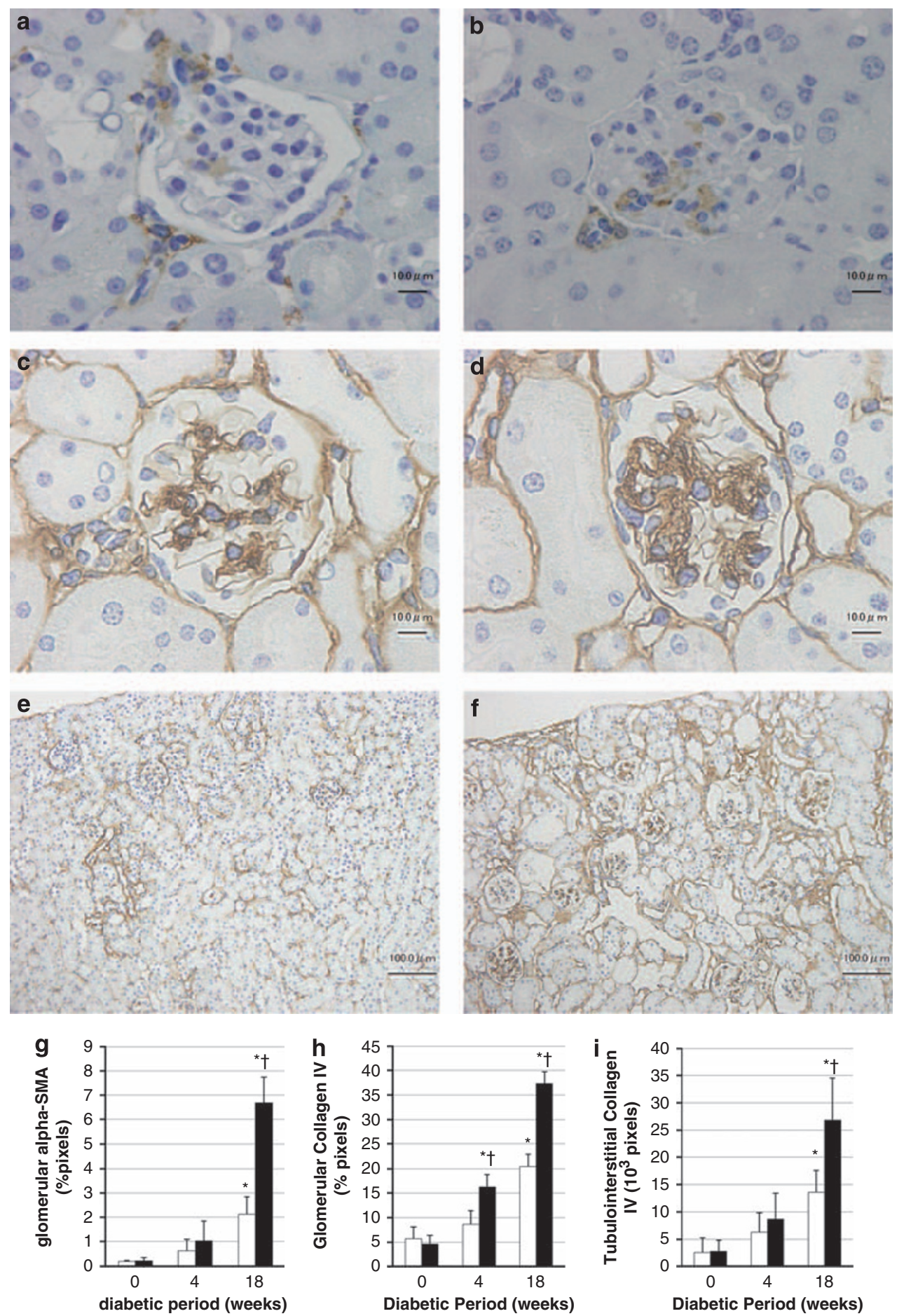

Figure 2 (a-f) Representative photomicrographs of immunohistochemical staining for glomerular $\alpha$-SMA (a, b) and for glomerular/tubulointerstitial collagen IV (c-f) in the kidneys of wild-type (a) and ACE2-KO mice (b) with 18 weeks of diabetes. Original magnification $\times 800$ (a-d) and $\times 200$ (e, f). (g-i) Quantification. White bars=wildtype $(n=6)$; black bars=ACE2-KO $(n=6)$. Data are presented as mean \pm s.e.m. ${ }^{*} P<0.05$ compared with a genotype-matched baseline group, and ${ }^{\dagger} P<0.05$ compared with age-matched wildtype.

diabetic wild-type mice (Figure $4 \mathrm{a}-\mathrm{f}, \mathrm{m}$ ). VEGF staining in the glomeruli showed a reverse pattern from the staining of nephrin; both types of diabetic mice showed a time-dependent increase in the expression of VEGF, which was more prominent in ACE2-KO mice than in wild-type mice (Figures $4 \mathrm{~g}-1, \mathrm{n}$ ).

\section{The effect of AT1 receptor blocker on nephropathy of diabetic ACE2-KO mice}

Treatment with Olmesartan did not affect body weight, blood glucose and blood pressure, but significantly decreased albuminuria, serum markers and glomerular/tubulointerstitial injury in both types of 

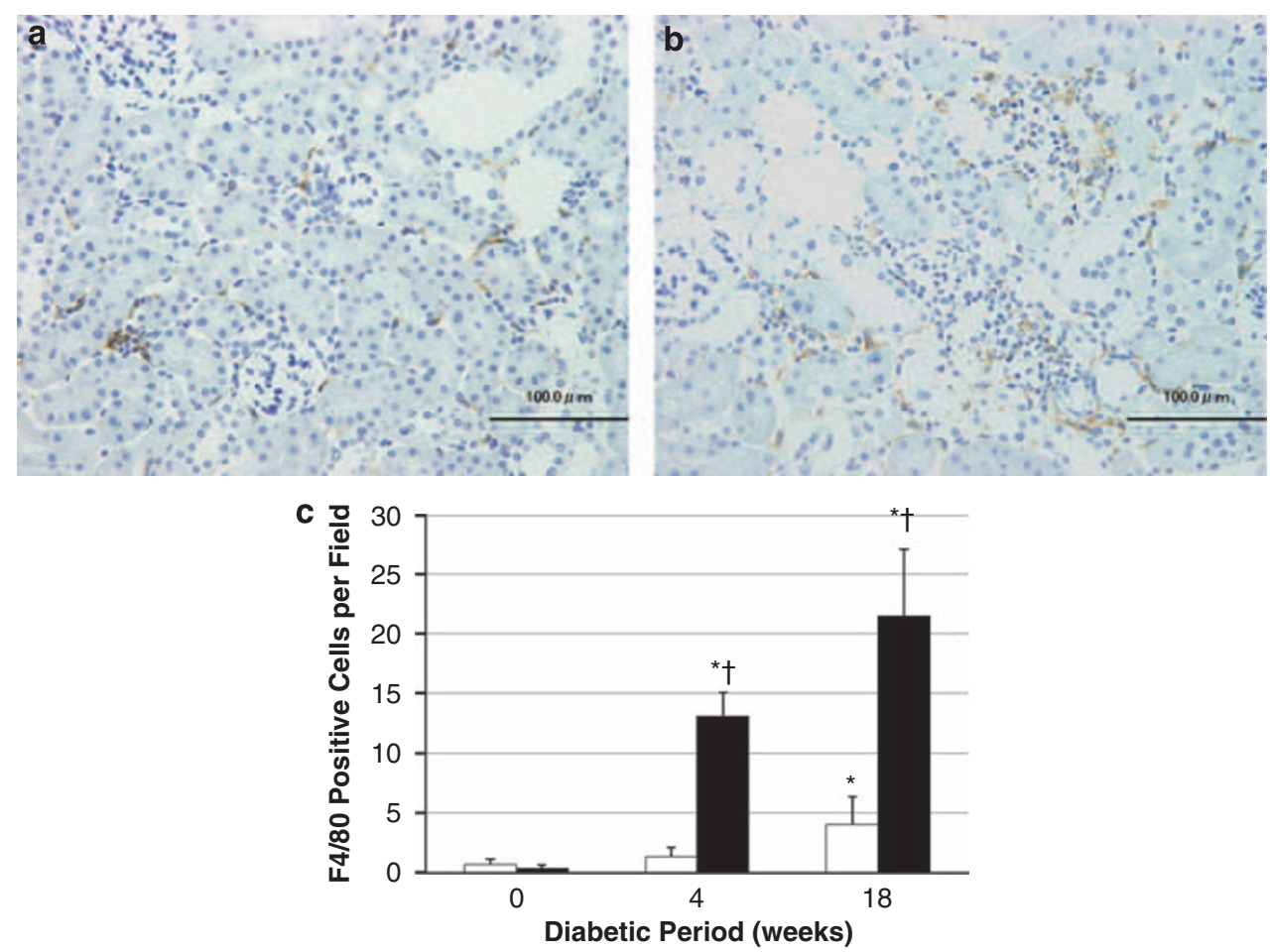

Figure 3 (a, b) Representative photomicrographs of F4/80 immunostained kidney sections from wild-type (a) and ACE2-KO mice (b) 18 weeks after induction of diabetes. Original magnification $\times 400$. (c) Quantification. White bars=wildtype $(n=6)$; black bars=ACE2-KO $(n=6)$. Data are presented as mean \pm s.e.m. ${ }^{*} P<0.05$ compared with a genotype-matched baseline group, and ${ }^{\dagger} P<0.05$ compared with age-matched wildtype.

mice, although there remained significant differences between the genotypes (Figure 5, Table 3).

\section{DISCUSSION}

In our study, ACE2 disruption in streptozotocin-induced diabetes resulted in an earlier onset of albuminuria and accelerated progression of glomerulosclerosis, tubular injury, macrophage infiltration, and interstitial fibrosis with increased serum blood urea nitrogen and creatinine. These findings imply that ACE2 might continuously protect from glomerular and tubulointerstitial injury during development of diabetic nephropathy.

Our findings of diabetic ACE2-KO mice are comparable with those of Wong et al., ${ }^{15}$ who used ACE2-KO mice crossed with Akita mice in models of type I diabetes, and showed more severe albuminuria and increased glomerular volume, mesangial matrix expansion and glomerular basement membrane thickness at 3 months of age. However, results of the recent report by Tikellis et al..$^{16}$ somewhat differed from our findings, where renal hypertrophy and fibrogenesis represented by renal mass increment and expression of PCNA, fibronectin and osteopontin were significantly attenuated by ACE2 disruption, but streptozotocin-induced diabetic ACE2-KO mice showed increased albuminuria 10 weeks after induction of diabetes in accordance with our study. These discrepancies might be due to differences in the source of ACE2-KO mice. Indeed, the ACE2-KO mice used in the previous study had a different cardiac phenotype from ours and other researchers, as reviewed in detail elsewhere. ${ }^{29}$ At any rate, the different findings from the previous report led us to observe detailed functional and morphological changes in diabetic ACE2-KO mice over time to clarify that our findings resulted purely from a disruption of the gene.
In immunohistological analysis, disruption of ACE2 enhanced the reduction of renal nephrin protein expression induced by diabetes. Glomerular epithelial cells (podocytes), as well as basement membrane and endothelial cells, are the main components of the filtration barrier. It is known that nephrin, a transmembrane protein in the immunoglobulin superfamily, is predominantly expressed in podocytes. Mutation of the nephrin gene is associated with severe congenital nephritic syndrome. ${ }^{30,31}$ In diabetic nephropathy, renal nephrin mRNA and protein expression are downregulated. ${ }^{28,32}$ Mechanism of nephrin downregulation in the diabetic milieu is unknown, but some reports suggest involvement of the RAS. ${ }^{26-28}$ In this experiment, disruption of ACE2 might induce negative regulation of nephrin expression, leading to early onset of albuminuria.

We also assessed VEGF expression. VEGF is an important signaling molecule in both vasculogenesis and angiogenesis. It involves in excess filtration and development of microalbuminuria in diabetes by increasing vascular permeability. ${ }^{33-35}$ In our study, diabetic ACE2$\mathrm{KO}$ mice showed a prominent increase in glomerular VEGF expression, suggesting the involvement of RAS in the regulation of VEGF expression, in accordance with past reports. ${ }^{36,37}$

In some previous reports, ARB inhibited increase of albuminuria in diabetic mice with genetical disruption or pharmacological inhibition of ACE2, comparable with vehicle-treated diabetic control mice. ${ }^{8,15}$ Our results showed that treatment with Olmesartan significantly ameliorated albuminuria as well as serum markers and renal histological change both in diabetic ACE2-KO and wild-type mice. As the difference in renal function between ACE2-KO and wild-type mice did not completely vanish by inhibition of Ang II signaling with Olmesartan, it is postulated that mechanism besides elevated Ang II might be involved in the renal phenotype of diabetic ACE2-KO mice. ACE2 

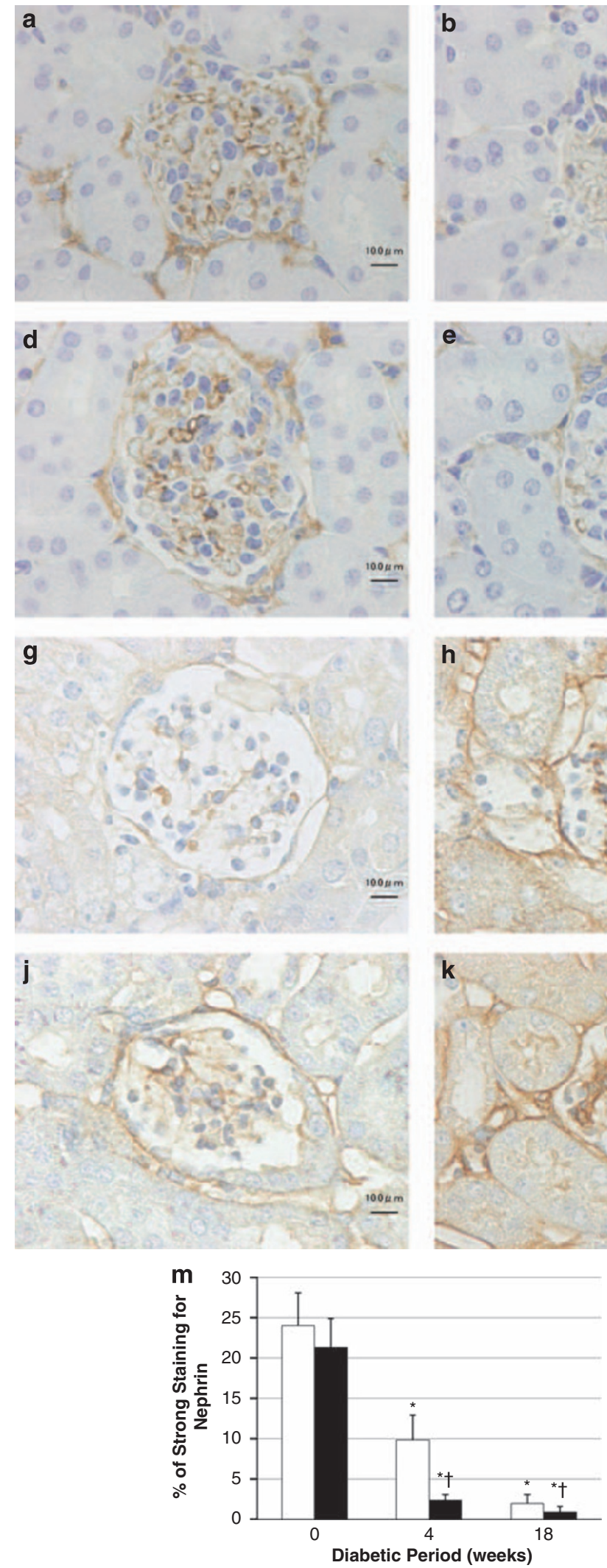
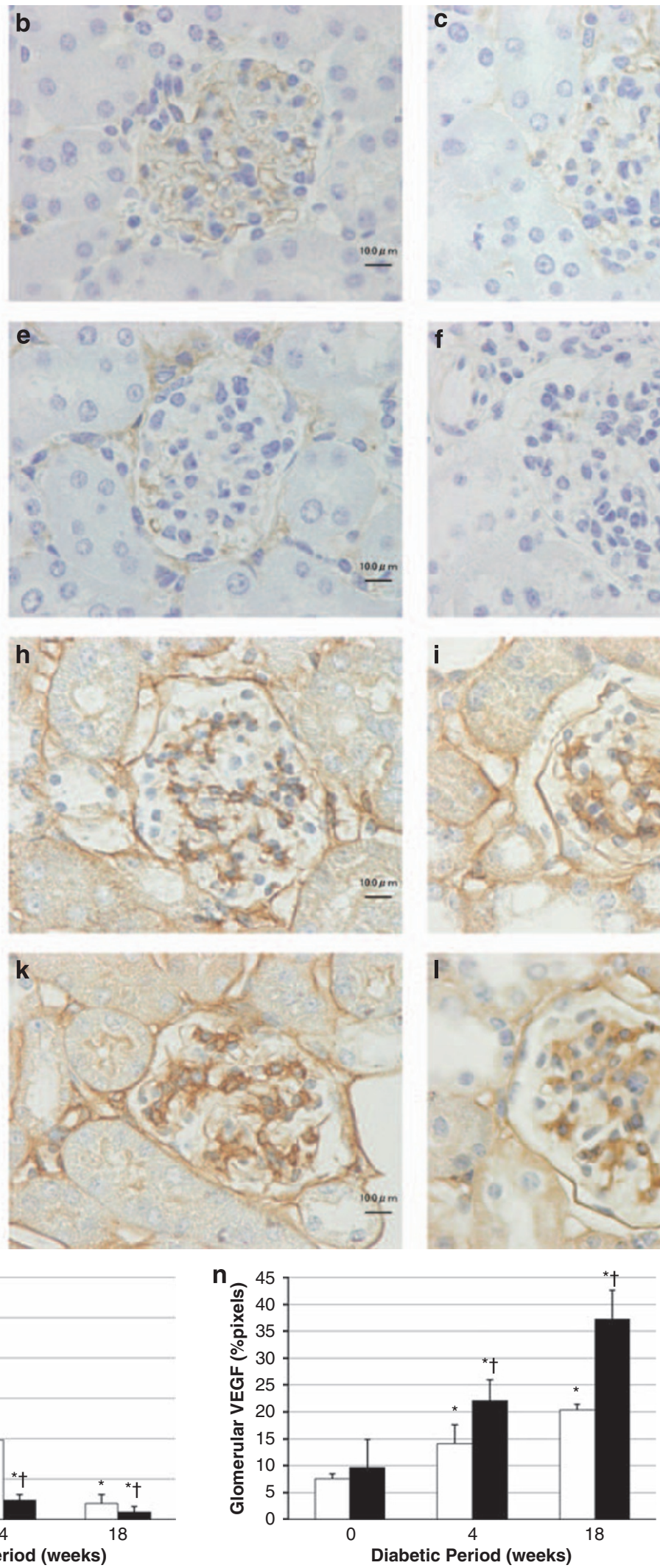

Figure 4 (a-f) Representative photomicrographs of immunohistochemical staining for nephrin in wild-type (a-c) and ACE2-KO mice (d-f); baseline (a, d), 4 weeks (b, e) and 18 weeks (c, f) after induction of diabetes. Original magnification $\times 800$. (g-l) Representative photomicrographs of immunohistochemical staining for VEGF in wild-type (g-i) and ACE2-KO mice (j-I); baseline $(\mathbf{g}, \mathbf{j}), 4$ weeks $(\mathbf{h}, \mathbf{k})$ and 18 weeks $(\mathbf{i}$, I) after induction of diabetes. Original magnification $\times 800$. $(\mathbf{m}, \mathbf{n})$ Quantification. White bars=wildtype $(n=6)$; black bars=ACE2-KO $(n=6)$. Data are presented as mean \pm s.e.m. ${ }^{*} P<0.05$ compared with genotype-matched baseline group, and ${ }^{\dagger} P<0.05$ compared with age-matched wildtype. 

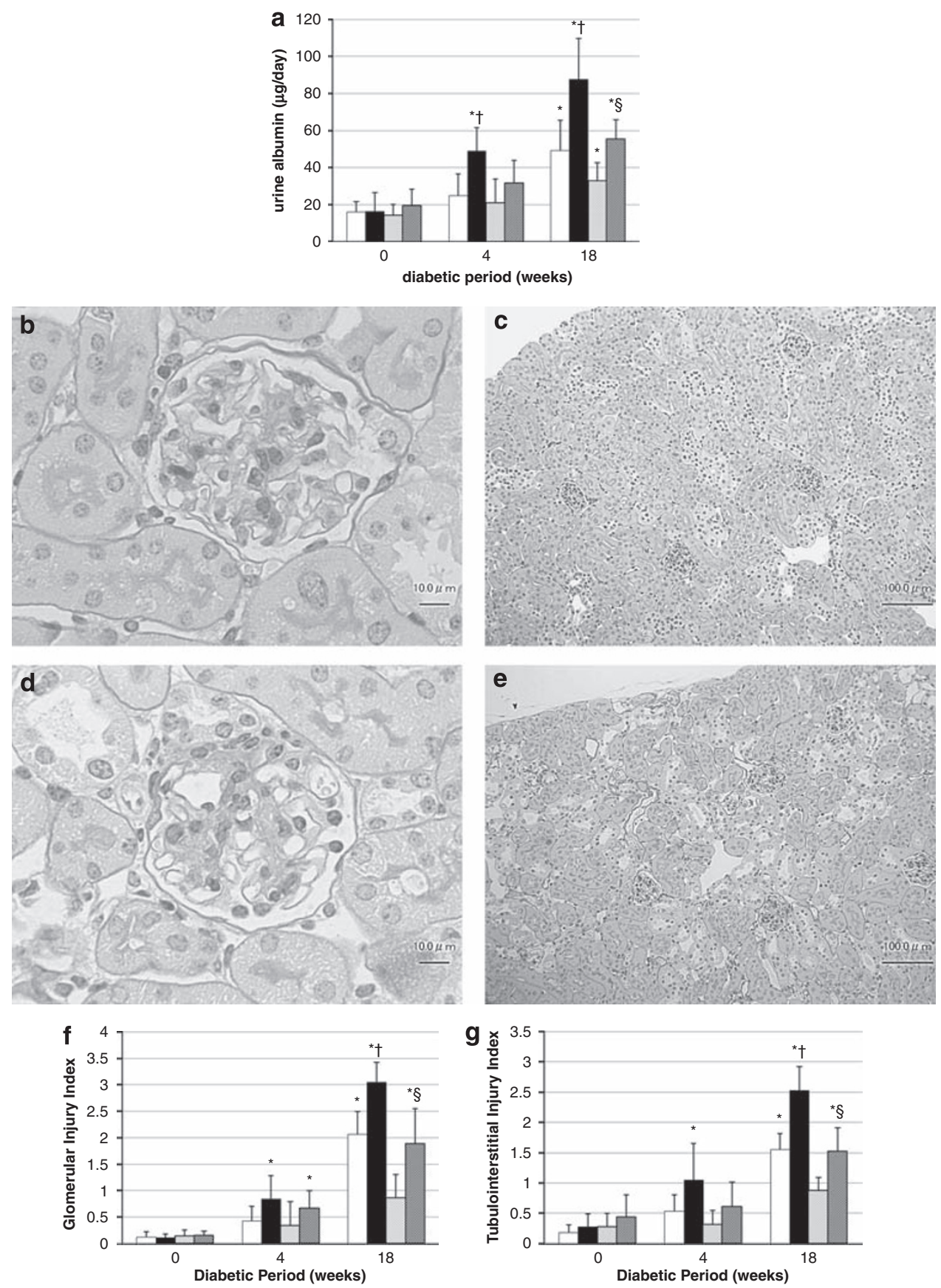

Figure 5 (a) Daily urinary albumin excretion of ACE2-KO and wild-type mice with or without administration of AT1 receptor blocker Olmesartan. (b-e) Representative photomicrographs of glomeruli and tubulointerstitium in PAS-stained kidney sections from ARB-treated wild-type (b, $\mathbf{c}$ ) and ACE2-KO mice (d, e) at 18 weeks of diabetes. Original magnifications $\times 800$ and $\times 200$. (f, g) Glomerular and tubulointerstitial injury index. White bars=wildtype; black bars=ACE2-KO; hatched bars=wild type+Olmesartan; slashed bars=ACE2-KO+ Olmesartan ( $n=10$ at each group). Data are presented as mean \pm s.e.m. ${ }^{*} P<0.05$ compared with genotype-matched baseline group, ${ }^{\dagger} P<0.05$ compared with age-matched wildtype, and ${ }^{\S} P<0.05$ vs. Olmesartantreated diabetic wildtype.

cleaves Ang II to produce Ang 1-7. Several physiological activities of Ang 1-7 are exerted through the Mas receptor, as previously reported. ${ }^{38}$ In the kidney, Mas is expressed mainly in tubules in the renal cortex. ${ }^{39}$ Some reports imply that Ang 1-7 has renoprotective effects. It was reported that Ang 1-7 attenuated sodium reabsorption caused by Ang II infusion, ${ }^{40}$ and that intrarenal Ang 1-7 blockade decreased the glomerular filtration rate, renal plasma flow, and sodium excretion in $1 \mathrm{~K} 1 \mathrm{C}$ hypertension, as well as salt-depleted SD and transgenic rats. ${ }^{41}$ These data suggest that Ang 1-7 exerts counterregulatory actions in response to the activation of the RAS. Thus, lack of Ang 1-7 might contribute to the phenotype of our diabetic ACE2KO mice. However, determining the contribution of decreased Ang 1-7 to renal damage is difficult in our model; studies in Mas receptor KO mice might be useful in elucidating any renal-protective effects.

In the nondiabetic state, ACE2-KO mice showed higher kidney Ang II concentrations than did wild-type mice, consistent with Crackower 
Table 3 Physiological and biochemical parameters of ARB-treated or untreated 18 weeks diabetic mice and nondiabetic control

\begin{tabular}{|c|c|c|c|c|c|c|}
\hline & $\begin{array}{c}\text { Nondiabetic } \\
\text { wildtype }(\mathrm{n}=10)\end{array}$ & $\begin{array}{c}\text { Nondiabetic } \\
\text { ACE2-KO }(\mathrm{n}=10)\end{array}$ & $\begin{array}{c}18 \text { Weeks diabetic } \\
\text { wildtype }(\mathrm{n}=10)\end{array}$ & $\begin{array}{l}18 \text { Weeks diabetic } \\
\text { ACE2-KO }(\mathrm{n}=10)\end{array}$ & $\begin{array}{l}18 \text { Weeks diabetic } \\
\text { wildtype treated with } \\
\text { Olmesartan }(\mathrm{n}=10)\end{array}$ & $\begin{array}{l}18 \text { Weeks diabetic } \\
\text { ACE2-KO treated with } \\
\text { Olmesartan }(\mathrm{n}=10)\end{array}$ \\
\hline Body weight (g) & $32 \pm 2.9$ & $34 \pm 1.9$ & $28 \pm 5.4$ & $30 \pm 4.7$ & $31 \pm 5.3$ & $31 \pm 3.6$ \\
\hline Mean blood pressure $(\mathrm{mm} \mathrm{Hg})$ & $77 \pm 12.4$ & $84 \pm 6.72$ & $76 \pm 11.3$ & $88 \pm 8.31$ & $64 \pm 19.8$ & $70 \pm 12.4$ \\
\hline Blood glucose $\left(\mathrm{mmol} \mathrm{I}^{-1}\right)$ & $14.2 \pm 1.38$ & $12.4 \pm 2.62$ & $24.0 \pm 3.85^{*}$ & $25.2 \pm 4.81^{*}$ & $28.2 \pm 5.72^{*}$ & $21.9 \pm 6.37^{*}$ \\
\hline Serum creatinine $(\mu \mathrm{mol} \mathrm{I}-1)$ & $16 \pm 1.24$ & $13 \pm 2.75$ & $23 \pm 0.97$ & $36 \pm 5.8^{*}, \dagger$ & $20 \pm 3.72$ & $27 \pm 4.31^{*}, \S$ \\
\hline Serum urea nitrogen $\left(\mathrm{mmoll}^{-1}\right)$ & $9.7 \pm 0.47$ & $10 \pm 0.93$ & $13 \pm 0.41^{*}$ & $19 \pm 1.3^{*}, \dagger$ & $8 \pm 1.75$ & $15 \pm 2.29^{*}, \S$ \\
\hline Serum $\mathrm{Na}\left(\mathrm{mmol} \mathrm{I}^{-1}\right)$ & $142 \pm 2.0$ & $139 \pm 3.8$ & $144 \pm 11$ & $145 \pm 9.1$ & $143 \pm 7.5$ & $141 \pm 7.7$ \\
\hline Kidney weight (mg) & $178 \pm 11.6$ & $166 \pm 21.0$ & $234 \pm 24.1^{*}$ & $242 \pm 36.7^{*}$ & $176 \pm 30$ & $203 \pm 42.5$ \\
\hline Heart weight (mg) & $137 \pm 8.50$ & $125 \pm 16.0$ & $126 \pm 19.5$ & $133 \pm 25.3$ & $118 \pm 10.8$ & $124 \pm 19.3$ \\
\hline
\end{tabular}

Abbreviations: ACE2-KO, angiotensin-converting enzyme-2-knockout; ARB, angiotensin II receptor blocker.

All groups of mice were age-matched. Data are presented as mean \pm s.e.m. ${ }^{*} P<0.05$ vs. genotype-matched nondiabetic group, ${ }^{\dagger} P<0.05$ vs. untreated diabetic wildtype, and ${ }^{\S} P<0.05$ vs. ARBtreated diabetic wildtype.

et al. ${ }^{25}$ However, after the administration of streptozotocin, kidney Ang II concentrations increased in both ACE2-KO and wild-type mice, but no significant difference was observed between the groups. These findings are consistent with Wong et al. ${ }^{15}$ who measured tissue Ang II concentrations in whole kidney. ACE2-KO mice showed similar levels of tissue Ang II to wild-type mice in the diabetic state. As previously discussed, whole kidney Ang II concentrations might not reflect local Ang II activity, because of the complex kinetics of Ang II production and distribution in the kidney. ${ }^{15,42}$ However, further investigations will be required to determine the influence of ACE2 on Ang II distribution in kidney.

In conclusion, ACE2 deletion caused accelerated renal damage in the development of diabetes, including not only glomerulopathy accompanied by albuminuria but also tubulointerstitial injury and eventual renal dysfunction. In addition to reducing Ang II, yielding Ang 1-7 might be involved in ACE2-mediated renal protection.

\section{ACKNOWLEDGEMENTS}

We are most grateful to Kazuko Iwasa at Osaka University for her technical assistance. We thank Dr Nancy Price at San Francisco Edit for her assistance in editing this paper.

1 Lewis EJ, Hunsicker LG, Bain RP, Rohde RD. The effect of angiotensin-convertingenzyme inhibition on diabetic nephropathy. The Collaborative Study Group. N Engl J Med 1993; 329: 1456-1462.

2 Lewis EJ, Hunsicker LG, Clarke WR, Berl T, Pohl MA, Lewis JB, Ritz E, Atkins RC, Rohde R, Raz I. Renoprotective effect of the angiotensin-receptor antagonist irbesartan in patients with nephropathy due to type 2 diabetes. N Engl J Med 2001; 345: 851-860.

3 Brenner BM, Cooper ME, de Zeeuw D, Keane WF, Mitch WE, Parving HH, Remuzzi G, Snapinn SM, Zhang Z, Shahinfar S. Effects of losartan on renal and cardiovascular outcomes in patients with type 2 diabetes and nephropathy. N Engl J Med 2001; 345: 861-869.

4 Carey RM, Siragy HM. The intrarenal renin-angiotensin system and diabetic nephropathy. Trends Endocrinol Metab 2003; 14: 274-281.

5 Wolf G, Ziyadeh FN. The role of angiotensin II in diabetic nephropathy: emphasis on nonhemodynamic mechanisms. Am J Kidney Dis 1997; 29: 153-163.

6 Donoghue M, Hsieh F, Baronas E, Godbout K, Gosselin M, Stagliano N, Donovan M, Woolf B, Robison K, Jeyaseelan R, Breitbart RE, Acton S. A novel angiotensinconverting enzyme-related carboxypeptidase (ACE2) converts angiotensin I to angiotensin 1-9. Circ Res 2000; 87: E1-E9.

7 Tipnis SR, Hooper NM, Hyde R, Karran E, Christie G, Turner AJ. A human homolog of angiotensin-converting enzyme. Cloning and functional expression as a captoprilinsensitive carboxypeptidase. J Biol Chem 2000; 275: 33238-33243.

8 Ye M, Wysocki J, William J, Soler MJ, Cokic I, Batlle D. Glomerular localization and expression of angiotensin-converting enzyme 2 and angiotensin-converting enzyme: implications for albuminuria in diabetes. J Am Soc Nephrol 2006; 17: 3067-3075.
9 Ye M. Increased ACE 2 and decreased ACE protein in renal tubules from diabetic mice: a renoprotective combination? Hypertension 2004; 43: 1120-1125.

10 Tikellis C, Johnston CI, Forbes JM, Burns WC, Burrell LM, Risvanis J, Cooper ME. Characterization of renal angiotensin-converting enzyme 2 in diabetic nephropathy. Hypertension 2003; 41: 392-397.

11 Hamming I, Timens W, Bulthuis ML, Lely AT, Navis GJ, van Goor H. Tissue distribution of ACE2 protein, the functional receptor for SARS coronavirus. A first step in understanding SARS pathogenesis. J Pathol 2004; 203: 631-637.

12 Mizuiri S, Hemmi H, Arita M, Ohashi Y, Tanaka Y, Miyagi M, Sakai K, Ishikawa Y, Shibuya $\mathrm{K}$, Hase H, Aikawa A. Expression of ACE and ACE2 in individuals with diabetic kidney disease and healthy controls. Am J Kidney Dis 2008; 51: 613-623.

13 Reich HN, Oudit GY, Penninger JM, Scholey JW, Herzenberg AM. Decreased glomerular and tubular expression of ACE2 in patients with type 2 diabetes and kidney disease. Kidney Int 2008; 74: 1610-1616.

14 Soler MJ, Wysocki J, Ye M, Lloveras J, Kanwar Y, Batlle D. ACE2 inhibition worsens glomerular injury in association with increased ACE expression in streptozotocininduced diabetic mice. Kidney Int 2007; 72: 614-623.

15 Wong DW, Oudit GY, Reich H, Kassiri Z, Zhou J, Liu QC, Backx PH, Penninger JM, Herzenberg AM, Scholey JW. Loss of angiotensin-converting enzyme-2 (ACE2) accelerates diabetic kidney injury. Am J Pathol 2007; 171: 438-451.

16 Tikellis C, Bialkowski K, Pete J, Sheehy K, Su Q, Johnston C, Cooper ME, Thomas MC. ACE2 deficiency modifies renoprotection afforded by ACE inhibition in experimental diabetes. Diabetes 2008; 57: 1018-1025.

17 Yamamoto K, Ohishi M, Katsuya T, Ito N, Ikushima M, Kaibe M, Tatara Y, Shiota A, Sugano S, Takeda S, Rakugi H, Ogihara T. Deletion of angiotensin-converting enzyme 2 accelerates pressure overload-induced cardiac dysfunction by increasing local angiotensin II. Hypertension 2006; 47: 718-726.

18 Lassila M, Seah KK, Allen TJ, Thallas V, Thomas MC, Candido R, Burns WC, Forbes JM, Calkin AC, Cooper ME, Jandeleit-Dahm KA. Accelerated nephropathy in diabetic apolipoprotein e-knockout mouse: role of advanced glycation end products. J Am Soc Nephrol 2004; 15: 2125-2138.

19 Mima A, Arai H, Matsubara T, Abe H, Nagai K, Tamura Y, Torikoshi K, Araki M, Kanamori H, Takahashi T, Tominaga T, Matsuura M, lehara N, Fukatsu A, Kita T, Doi T. Urinary Smad1 is a novel marker to predict later onset of mesangial matrix expansion in diabetic nephropathy. Diabetes 2008; 57: 1712-1722.

20 Ohtomo S, Ito M, Izuhara Y, Van Ypersele De Strihou C, Miyata T. Reduction of albuminuria by angiotensin receptor blocker beyond blood pressure lowering: evaluation in megsin/receptor for advanced glycation end products/inducible nitric oxide synthase triple transgenic diabetic nephropathy mouse model. Nephrology (Carlton) 2008; 13: 517-521.

21 Sonta $T$, Inoguchi $T$, Matsumoto $S$, Yasukawa $K$, Inuo M, Tsubouchi $H$, Sonoda N, Kobayashi K, Utsumi $\mathrm{H}$, Nawata $\mathrm{H}$. In vivo imaging of oxidative stress in the kidney of diabetic mice and its normalization by angiotensin II type 1 receptor blocker. Biochem Biophys Res Commun 2005; 330: 415-422.

22 Nicholas SB, Aguiniga E, Ren Y, Kim J, Wong J, Govindarajan N, Noda M, Wang W, Kawano Y, Collins A, Hsueh WA. Plasminogen activator inhibitor-1 deficiency retards diabetic nephropathy. Kidney Int 2005; 67: 1297-1307.

23 de Haan JB, Stefanovic N, Nikolic-Paterson D, Scurr LL, Croft KD, Mori TA, Hertzog P, Kola I, Atkins RC, Tesch GH. Kidney expression of glutathione peroxidase-1 is not protective against streptozotocin-induced diabetic nephropathy. Am J Physiol Renal Physiol 2005; 289: F544-F551.

24 Pillebout E, Weitzman JB, Burtin M, Martino C, Federici P, Yaniv M, Friedlander G, Terzi F. JunD protects against chronic kidney disease by regulating paracrine mitogens. J Clin Invest 2003; 112: 843-852.

25 Crackower MA, Sarao R, Oudit GY, Yagil C, Kozieradzki I, Scanga SE, Oliveira-dosSantos AJ, da Costa J, Zhang L, Pei Y, Scholey J, Ferrario CM, Manoukian AS, Chappell MC, Backx PH, Yagil Y, Penninger JM. Angiotensin-converting enzyme 2 is an essential regulator of heart function. Nature 2002; 417: 822-828. 
26 Bonnet F, Cooper ME, Kawachi H, Allen TJ, Boner G, Cao Z. Irbesartan normalises the deficiency in glomerular nephrin expression in a model of diabetes and hypertension. Diabetologia 2001; 44: 874-877.

27 Davis BJ, Cao Z, de Gasparo M, Kawachi H, Cooper ME, Allen TJ. Disparate effects of angiotensin II antagonists and calcium channel blockers on albuminuria in experimental diabetes and hypertension: potential role of nephrin. J Hypertens 2003; 21: 209-216.

28 Doublier S, Salvidio G, Lupia E, Ruotsalainen V, Verzola D, Deferrari G, Camussi G. Nephrin expression is reduced in human diabetic nephropathy: evidence for a distinct role for glycated albumin and angiotensin II. Diabetes 2003; 52: 1023-1030.

29 Gurley SB, Coffman TM. Angiotensin-converting enzyme 2 gene targeting studies in mice: mixed messages. Exp Physiol 2008; 93: 538-542.

30 Kestila M, Lenkkeri U, Mannikko M, Lamerdin J, McCready P, Putaala H, Ruotsalainen V, Morita T, Nissinen M, Herva R, Kashtan CE, Peltonen L, Holmberg C, Olsen A, Tryggvason K. Positionally cloned gene for a novel glomerular proteinnephrin-is mutated in congenital nephrotic syndrome. Mol Cell 1998; 1: 575-582.

31 Lenkkeri U, Mannikko M, McCready P, Lamerdin J, Gribouval O, Niaudet PM, Antignac CK, Kashtan CE, Homberg C, Olsen A, Kestila M, Tryggvason K. Structure of the gene for congenital nephrotic syndrome of the finnish type (NPHS1) and characterization of mutations. Am J Hum Genet 1999; 64: 51-61.

32 Benigni A, Gagliardini E, Tomasoni S, Abbate M, Ruggenenti P, Kalluri R, Remuzzi G. Selective impairment of gene expression and assembly of nephrin in human diabetic nephropathy. Kidney Int 2004; 65: 2193-2200.

33 Hohenstein B, Hausknecht B, Boehmer K, Riess R, Brekken RA, Hugo CP. Local VEGF activity but not VEGF expression is tightly regulated during diabetic nephropathy in man. Kidney Int 2006; 69: 1654-1661.

34 Hovind P, Tarnow L, Oestergaard PB, Parving HH. Elevated vascular endothelial growth factor in type 1 diabetic patients with diabetic nephropathy. Kidney Int Supp/2000; 75: S56-S61.
35 Kim NH, Oh JH, Seo JA, Lee KW, Kim SG, Choi KM, Baik SH, Choi DS, Kang YS, Han SY, Han KH, Ji YH, Cha DR. Vascular endothelial growth factor (VEGF) and soluble VEGF receptor FLT-1 in diabetic nephropathy. Kidney Int 2005; 67: 167-177.

36 Chen S, Lee JS, Iglesias-de la Cruz MC, Wang A, Izquierdo-Lahuerta A, Gandhi NK, Danesh FR, Wolf G, Ziyadeh FN. Angiotensin II stimulates alpha3(IV) collagen production in mouse podocytes via TGF-beta and VEGF signalling: implications for diabetic glomerulopathy. Nephrol Dial Transplant 2005; 20: 1320-1328.

37 Kakizawa H, Itoh Y, Imamura S, Matsumoto T, Ishiwata Y, Ono Y, Yamamoto K, Kato T, Hayakawa N, Oda N, Goto Y, Nagasaka A, Senda T, Itoh M. Possible role of VEGF in the progression of kidney disease in streptozotocin (STZ)-induced diabetic rats: effects of an ACE inhibitor and an angiotensin II receptor antagonist. Horm Metab Res 2004; 36: 458-464.

38 Santos RA, Simoes e Silva AC, Maric C, Silva DM, Machado RP, de Buhr I, HeringerWalther S, Pinheiro SV, Lopes MT, Bader M, Mendes EP, Lemos VS, CampagnoleSantos MJ, Schultheiss HP, Speth R, Walther T. Angiotensin-(1-7) is an endogenous ligand for the G protein-coupled receptor Mas. Proc Natl Acad Sci USA 2003; 100: 8258-8263.

39 Alenina N, Xu P, Rentzsch B, Patkin EL, Bader M. Genetically altered animal models for Mas and angiotensin-(1-7). Exp Physiol 2008; 93: 528-537.

40 Burgelova M, Kramer HJ, Teplan V, Thumova M, Cervenka L. Effects of angiotensin(1-7) blockade on renal function in rats with enhanced intrarenal Ang II activity. Kidney Int 2005; 67: 1453-1461.

41 Burgelova M, Kramer HJ, Teplan V, Velickova G, Vitko S, Heller J, Maly J, Cervenka L. Intrarenal infusion of angiotensin-(1-7) modulates renal functional responses to exogenous angiotensin II in the rat. Kidney Blood Press Res 2002; 25: 202-210.

42 Schalekamp MA, Danser AH. Angiotensin II production and distribution in the kidney: I. A kinetic model. Kidney Int 2006; 69: 1543-1552.

Supplementary Information accompanies the paper on Hypertension Research website (http://www.nature.com/hr) 